\title{
Critical Heat Flux with Subcooled Flowing Water in Tubes for Pressures from Atmosphere to Near-Critical Point
}

\author{
Yuzhou Chen, Keming Bi, Minfu Zhao, Chunsheng Yang and Kaiwen Du \\ Department of Reactor Engineering Research and Design, China Institute of Atomic Energy, Beijing 102413, China
}

Received: February 15, 2016 / Accepted: March 08, 2016 / Published: April 30, 2016.

\begin{abstract}
During last 45 years, two groups of the experimental data on critical heat flux were obtained in bare tubes, covering the pressures from atmosphere to near-critical point. One group of the data were obtained in the inner diameter of 2.32, 5.16, 8.05, 10.0 and $16.0 \mathrm{~mm}$, respectively, with the ranges of pressure of $0.1-1.92 \mathrm{MPa}$, velocity of $1.47-23.3 \mathrm{~m} / \mathrm{s}$, local subcooling of $3.7-108.7{ }^{\circ} \mathrm{C}$ and heat flux of up to $38.3 \mathrm{MW} / \mathrm{m}^{2}$. Another group of the data were obtained in the inner diameter of $4.62,7.98$ and $10.89 \mathrm{~mm}$, respectively, with the ranges of pressure of 1.7-20.6 MPa, mass flux of 454-4,055 kg/(m $\cdot \mathrm{s})$ and inlet subcooling of $53-361{ }^{\circ} \mathrm{C}$. The results showed complicated effects of the pressure, mass flux, subcooling and diameter on the critical heat flux. They were formulated by two empirical correlations. A mechanistic model on the limit of heat transfer capability from the bubbly layer to the subcooled core was also proposed for all the results.
\end{abstract}

Key words: Critical heat flux, near-critical pressure, atmosphere, subcooled water.

\section{Nomenclature}

$C_{p} \quad$ Specific heat at constant pressure, $\mathrm{J} /(\mathrm{kg} \cdot \mathrm{K})$

$D \quad$ Inner diameter, $\mathrm{m}$ or $\mathrm{mm}$

DT Subcooling, $\mathrm{K}$

$f \quad$ Friction factor

$f(\beta) \quad$ Function of contact angle with surface

$G \quad$ Mass flux, $\mathrm{kg} /\left(\mathrm{m}^{2} \cdot \mathrm{s}\right)$

$H \quad$ Enthalpy, $\mathrm{J} / \mathrm{kg}$

ID Inner diameter, $\mathrm{mm}$

$O D \quad$ Outer diameter, $\mathrm{mm}$

$L \quad$ Heated length, m

- $\quad$ Mass flow rate, $\mathrm{kg} / \mathrm{s}$

$m$
$P$ Pressure, $\mathrm{MPa}$

Pr Prandtl number

$q \quad$ Heat flux, $\mathrm{W} / \mathrm{m}^{2}$

$q_{C H F} \quad$ Critical heat flux, $\mathrm{MW} / \mathrm{m}^{2}$

Re Reynolds number

$Q \quad$ Non-dimentional parameter, $Q=\frac{q}{\rho_{l} C_{p l} U_{\tau}}$

$r \quad$ Radius, $\mathrm{m}$

Corresponding author: Yuzhou Chen, professor, research fields: nuclear safety and thermal-hydraulics.
$T \quad$ Temperature, $\mathrm{K}$

$y \quad$ Distance from the heated surface, $\mathrm{m}$

$y^{+} \quad$ Non-dimentional distance

$U \quad$ Velocity, $\mathrm{m} / \mathrm{s}$

$\bar{U}_{B} \quad$ Average velocity of bubbly layer, $\mathrm{m} / \mathrm{s}$

$U_{\tau} \quad$ Friction velocity, $\left(\tau_{w} / \rho_{l}\right)^{0.5}, \mathrm{~m} / \mathrm{s}$

$U^{+} \quad$ Non-dimentional velocity, $y U_{\tau} / v_{l}$

$A V G \quad$ Average error

$R M S \quad$ Standard error

$\sigma \quad$ Surface tension, $\mathrm{N} / \mathrm{m}$

$\delta_{B} \quad$ Thickness of bubbly layer, $\mathrm{m}$

$\alpha \quad$ Void fraction

$\varepsilon \quad$ Surface roughness, $\mathrm{m}$

$\rho \quad$ Density, $\mathrm{kg} / \mathrm{m}^{3}$

$\tau_{w} \quad$ Wall shear stress, $\mathrm{N}$

$v \quad$ Kinematic viscosity, $\mathrm{m}^{2} / \mathrm{s}$

\section{Subscript}

B Bubble

C Liquid core

c Calculation

E Experiment

g Steam 


$\begin{array}{ll}\mathrm{i} & \text { Inlet } \\ 1 & \text { Liquid } \\ \mathrm{o} & \text { Outlet } \\ \mathrm{s} & \text { Saturation }\end{array}$

\section{Introduction}

CHF (critical heat flux) is a major limit for the safety of nuclear reactors, because the occurrence of CHF could lead to a failure of fuel element [1-3]. During past six decades, the CHF has been investigated extensively over the world, and a variety of prediction methods have been proposed, including the empirical correlations, the physical models and the look-up tables [3-20]. Because of the extreme complexity of the phenomena and the lack of adequate knowledge of the mechanisms, all these predictive methods are heavily relied on the experimental data. For the CHF of near-critical pressures, which is interest for the SCWR (supercritical water-cooled reactors), only a limited experimental data have been published in Refs. [21-24].

In CIAE (China Institute of Atomic Energy), a great number of CHF experimental data of subcooled flow water were obtained at lower pressure to support the designs of research reactors, including the $\mathrm{CHF}$ in the rod bundle and the annuli heated from one-side or both-sides at steady-state or transient conditions [25-27]. They were the HWRR (heavy water research reactor), the HFR (high flux reactor) and the CARR (China advance research reactor), and were first put into operation in 1957, 1980 and 2011, respectively. During this period, the CHF experiments were also performed in the stainless-steel tubes of inner diameter of $D=2.32-16 \mathrm{~mm}$ at pressures less than $2 \mathrm{MPa}[28,29]$. In recent years, the research was extended to the near critical pressure for the SCWR, and the experiments were performed in the Inconel-625 tubes of 4.62, 7.98 and $10.89 \mathrm{~mm}$ in diameter [30-32]. In the present investigation, the parametric trends were studied, and the empirical correlations were formulated. Based on all the subcooled experimental results, a mechanistic model on the limit of the enthalpy of bubbly layer was proposed.

\section{Experiment}

\subsection{Experimental Facilities and Test Sections}

Two test facilities were used: (i) supercritical water test facility, and (ii) lower pressure test loop. In the former one, a three-head piston pump was applied to drive the de-ioned water through the dumping tank, the preheater, the test section, the heat exchanger and then to the water tank. The water flowed upward through the test sections. They were heated uniformly by a DC supply with capacity of 7,000 A $\times 65 \mathrm{~V}$. The preheater was heated by an AC supply. The experiments were performed by keeping the test power and the flow rate constants but increasing the preheater power slowly to approach the $\mathrm{CHF}$ condition. In the latter one, a centrifugal pump was applied to drive the de-ioned water. It flowed downward through the test sections. They were heated uniformly by a DC supply with capacity of $15,000 \mathrm{~A} \times 75 \mathrm{~V}$. The experiments were performed by keeping the test power and flow rate constants but controlling the flow rate of the cooling water of heat exchanger to increase the water temperature slowly, until the $\mathrm{CHF}$ occurred. In all the experiments, the onset of CHF was detected by photocells [33]. Because the test section was heated uniformly the CHF always occurred near the end of heated length. The details of the experimental facility and the procedures were described in the previous papers.

For higher pressure, three test sections of Inconel-625 tubes were used: (i) $4.62 \mathrm{~mm} I D$ (inner diameter), $6.5 \mathrm{~mm}$ $O D$ (outer diameter) and $0.5 \mathrm{~m}$ in heated length, (ii) $7.98 \mathrm{~mm} I D, 9.6 \mathrm{~mm} O D$ and $0.8 \mathrm{~m}$ in heated length, and (iii) $10.89 \mathrm{~mm} I D, 12.7 \mathrm{~mm} O D$ and $1.1 \mathrm{~m}$ in heated length. For lower pressure, five test sections of stainless-steel tubes were used. The inner diameters were: (i) $2.32 \mathrm{~mm}$, (ii) $5.16 \mathrm{~mm}$, (iii) $8.05 \mathrm{~mm}$, (iv) $10.0 \mathrm{~mm}$ and (v) $16.0 \mathrm{~mm}$. The details of geometries were listed in Table 2.

Major measurements of the parameters included: the outlet pressure, the flow rate, the inlet and outlet 
water temperatures of the test section, and the voltage and current across the heated tube. The readings were recorded by a data acquisition system or a multi-pen recorder (before 1980).

\subsection{Experimental Results}

\subsubsection{Higher Pressure}

The geometries and experimental conditions are listed in Table 1.

Fig. 1 shows the variations of critical heat flux, $q_{C H F}$, with inlet subcooling, $D T_{i}$, and local subcooling, $D T_{o}$, for different pressures. The $q_{C H F}$ increases with the subcooling, $D T_{i}$ or $D T_{o}$, increasing, and at higher pressure, the slope decreases. When the pressure exceeds $18 \mathrm{MPa}$, the variations of $q_{C H F}$ with subcooling are weak, and the $q_{C H F}$ is much lower than lower pressure due to the substantial decrease in the surface tension of the water. For a given high $D T_{o}$ higher $q_{C H F}$ corresponds to lower pressure, but at low $D T_{o}$ lower $q_{C H F}$ is obtained at rather low pressure.

The effect of mass flux on the CHF is shown in Fig. 2, indicating the $q_{C H F}$ increase with the increase of mass flux for the same pressure. Fig. 3 shows the effect of diameter on the CHF. For the nearly same pressure and mass flux, higher heat flux is obtained in smaller diameter. This effect is also observed by the other investigations, but the factor $D^{n}$ is different with the exponent $n$ from -0.1 to -0.5 [3].

An empirical formulation for the previous experiment of $D=7.98 \mathrm{~mm}$ was proposed as:

$$
q_{C H F}=c q_{s}
$$

where, $q_{s}$ was the heat flux for the exit to reach the saturation temperature, evaluated by:

$$
q_{s}=\frac{\left(H_{s}-H_{i}\right) G D}{4 L}
$$

where, $H_{i}$ and $H_{s}$ are the inlet enthalpy and saturation enthalpy, respectively, in $\mathrm{J} / \mathrm{kg}, G$ is the mass flux in $\mathrm{kg} /\left(\mathrm{m}^{2} \cdot \mathrm{s}\right), D$ is the inner diameter and $L$ is the heated length in $\mathrm{m}$. In the present investigation, the factor $c$ is modified to account for the three tubes as:

$$
c=\operatorname{Min}\left[\begin{array}{l}
2,350(1-0.0307 P) \\
\left(G\left(H_{s}-H_{i}\right)\right)^{-0.35}(D / 0.008)^{-0.35}, 1.0
\end{array}\right]
$$

where, $P$ is the pressure in MPa.

Table 1 The geometries and experimental conditions for higher pressures.

\begin{tabular}{lllllll}
\hline $\begin{array}{l}D / L \\
(\mathrm{~mm} / \mathrm{m})\end{array}$ & $\begin{array}{l}P \\
(\mathrm{MPa})\end{array}$ & $\begin{array}{l}G \\
\left(\mathrm{~kg} /\left(\mathrm{m}^{2} \cdot \mathrm{s}\right)\right)\end{array}$ & $\begin{array}{l}D T_{i} \\
(\mathrm{~K})\end{array}$ & $\begin{array}{l}D T_{o} \\
(\mathrm{~K})\end{array}$ & $\begin{array}{l}q_{C H F} \\
\left(\mathrm{MW} / \mathrm{m}^{2}\right)\end{array}$ & Number of data \\
\hline $4.62 / 0.5$ & $1.8-20.6$ & $556-4,055$ & $110-354$ & $1-169$ & $0.77-9.3$ & 118 \\
$7.98 / 0.8$ & $2.0-20.4$ & $476-1,653$ & $53-361$ & $3-158$ & $0.26-4.95$ & 193 \\
$10.89 / 1.1$ & $1.7-20.0$ & $454-1,144$ & $169-345$ & $4-141$ & $0.92-3.3$ & 74 \\
\hline
\end{tabular}

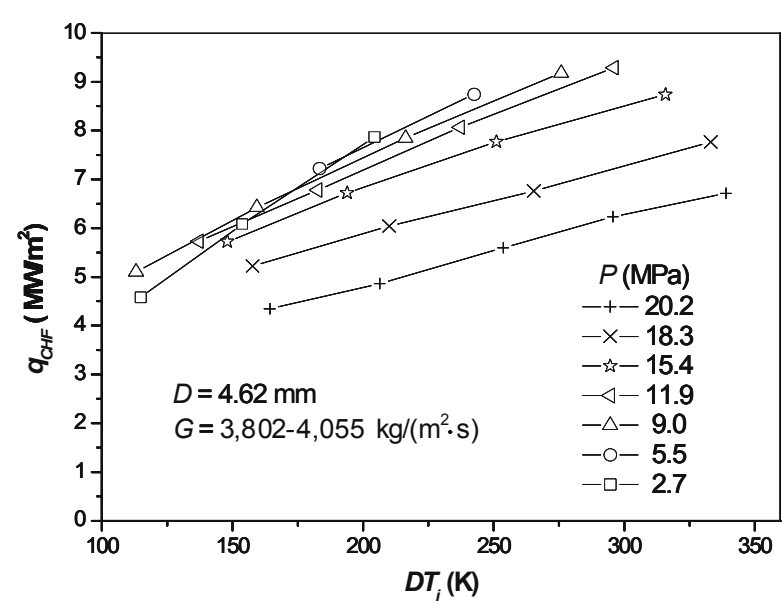

(a)

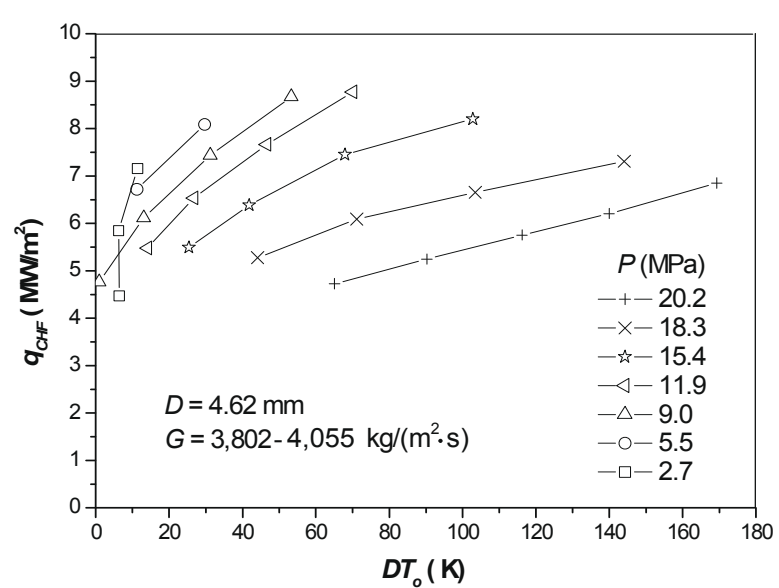

(b)

Fig. 1 Variations of CHF with inlet and local subcooling for different pressures. 


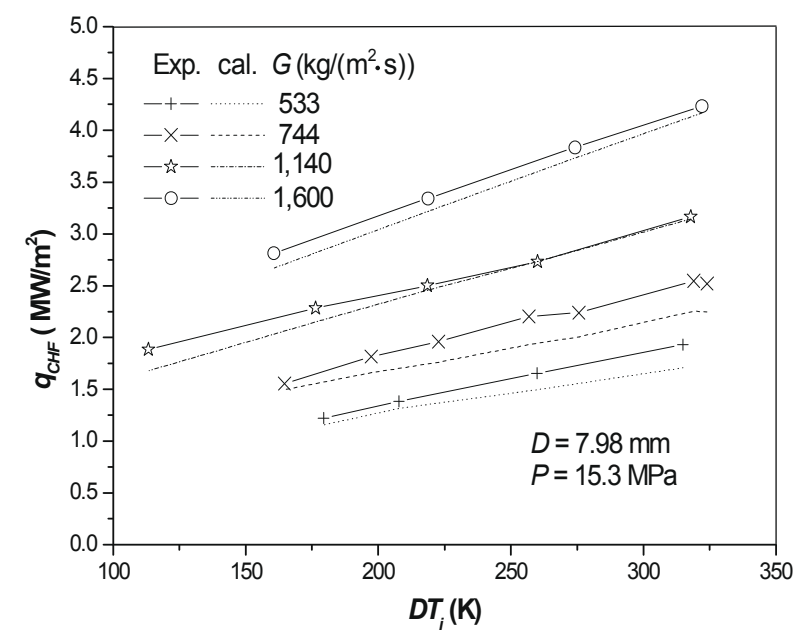

(a)

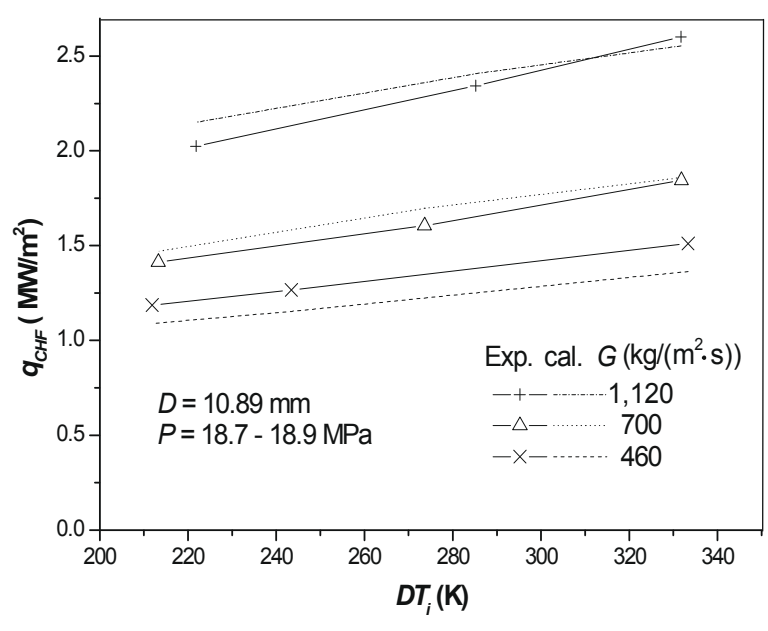

(b)

Fig. 2 The effect of inlet subcooling on the CHF for different mass fluxes (cal.-mechanistic model).

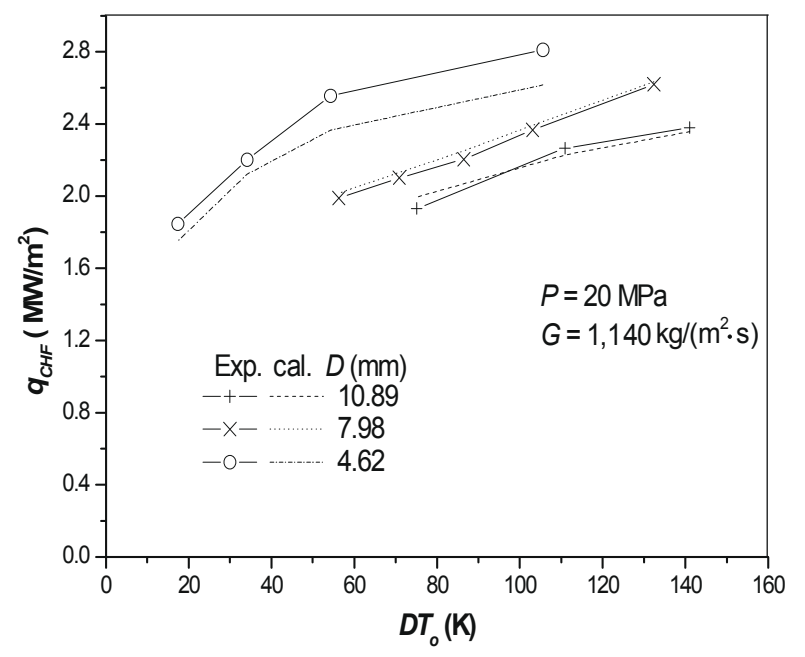

Fig. 3 The effect of diameter on the CHF (cal.-mechanistic model).

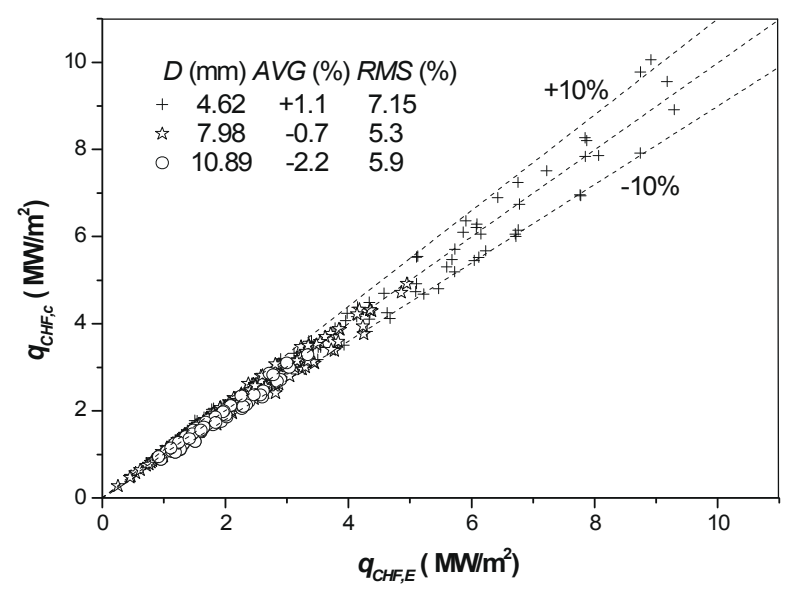

Fig. 4 Comparison of the experimental data with calculations of Eqs. (1) and (2) for higher pressures.
The comparison between the calculations by this correlation and the experimental data is shown in Fig. 4. The deviations of more than $90 \%$ of the data points are less than $10 \%$, and the average error, $A V G$, and the standard error, $R M S$, are $-0.43 \%$ and $6.0 \%$, respectively.

\subsubsection{Lower Pressure}

For the experimental data of $D=2.32,5.16,8.05$, 10.0 and $16.0 \mathrm{~mm}$, the experimental conditions cover the ranges of pressures of 0.1-1.92 MPa, local subcoolings of $3.7-108.7^{\circ} \mathrm{C}$, velocities of $1.47-23.3 \mathrm{~m} / \mathrm{s}$ and critical heat flux of up to $38.3 \mathrm{MW} / \mathrm{m}^{2}$. The geometries and the conditions are listed in Table 2.

It is recognized that, for subcooled critical heat flux with $L>200 \mathrm{~mm}$ and $D T_{o}>30 \mathrm{~K}$, the effect of heated length on the CHF disappears [8, 28, 29]. For the tube of $D=2.32 \mathrm{~mm}$, the heated length is smaller, but the ratio of $L / D$ exceeds 40 . Therefore, the effect of heated length for these five tubes is negligible.

The effects of local subcooling, mass flux, pressure and diameter on the CHF are shown in Figs. 5-7. The CHF increases with the $G$ and $D T_{o}$ increasing. This is similar with the finding of other investigations. Because of the differences in the geometries and experimental conditions, these effects are different greatly in literature, and thus the results can not be compared at the extended conditions [4-10]. 
Table 2 The geometries and experimental conditions for lower pressures.

\begin{tabular}{llllllll}
\hline \multirow{2}{*}{ No. } & Diameter & Heated length & Pressure & Velocity & Subcooling & $q_{C H F}$ & \multirow{2}{*}{ Number of data } \\
& $D(\mathrm{~mm})$ & $L(\mathrm{~m})$ & $P(\mathrm{MPa})$ & $V(\mathrm{~m} / \mathrm{s})$ & $\Delta T_{o}(\mathrm{~K})$ & $\left(\mathrm{MW} / \mathrm{m}^{2}\right)$ & 112 \\
\hline 1 & 2.32 & 0.098 & $0.10-1.68$ & $4.35-23.3$ & $3.7-100.9$ & $11.6-38.3$ & 63 \\
2 & 5.16 & 0.255 & $0.13-1.78$ & $2.59-22.3$ & $6.2-89.6$ & $8.4-29.3$ & 65 \\
3 & 8.05 & $0.383,0.396$ & $0.14-1.92$ & $1.88-15.9$ & $8.3-88.2$ & $4.7-17.9$ & 53 \\
4 & 10.0 & $0.295,0.400$ & $0.15-1.66$ & $3.39-9.26$ & $30.3-89.5$ & $4.4-10.9$ & 56 \\
5 & 16.0 & $0.295,0.390$ & $0.19-1.29$ & $1.47-13.4$ & $36.7-108.7$ & $4.2-14.6$ & 56 \\
\hline
\end{tabular}

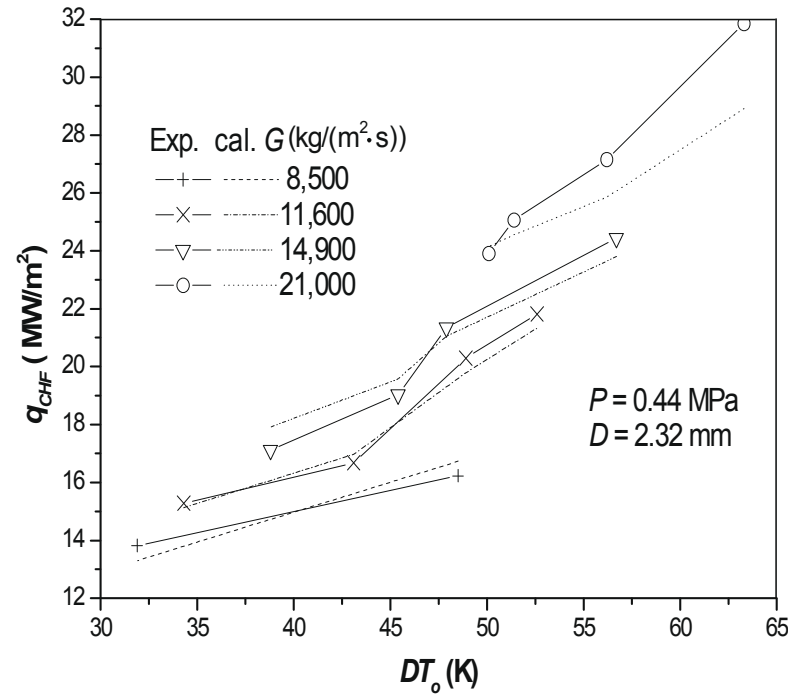

Fig. 5 The effects of local subcooling and mass flux on the CHF (cal.-mechanistic model).

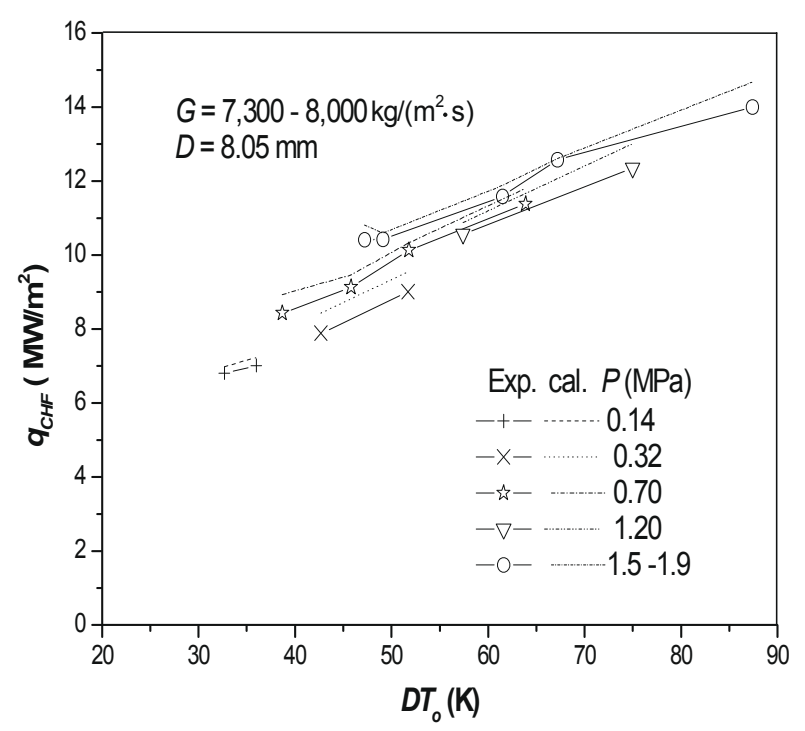

Fig. 6 The effect of pressure on the CHF (cal.-mechanistic model).

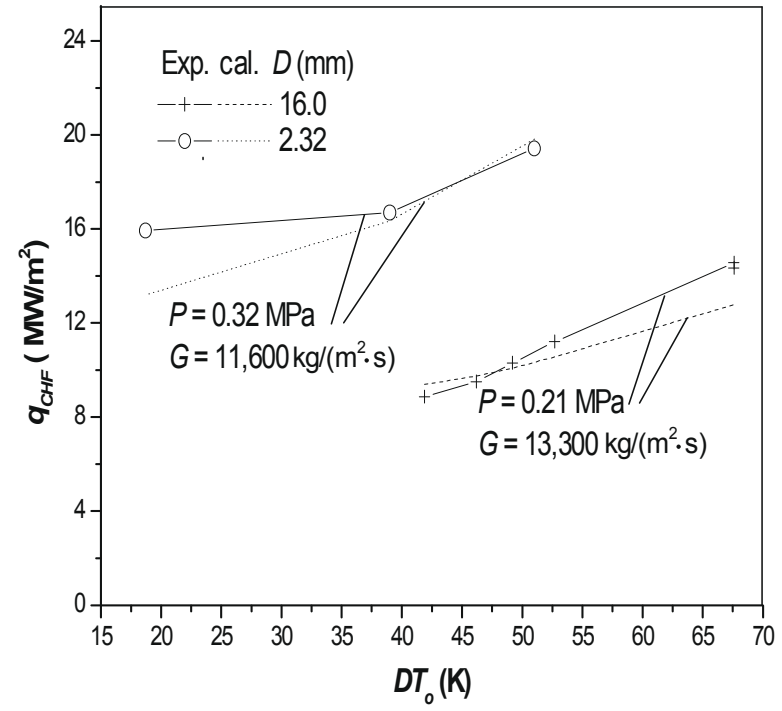

Fig. 7 The effect of diameter on the CHF (cal.-mechanistic model).

An empirical correlation is proposed for the experimental data of $D T_{o}>35 \mathrm{~K}$, as:

$$
\begin{aligned}
& q_{C H F}=0.108(1+0.104 V) \\
& \left(15 P+D T_{o}^{1-0.1 P}\right)\left(\frac{D}{0.008}\right)^{-0.35}
\end{aligned}
$$

where, the critical heat flux $q_{C H F}$ is in $\mathrm{MW} / \mathrm{m}^{2}$, velocity $V$ in $\mathrm{m} / \mathrm{s}$, pressure $P$ in $\mathrm{MPa}$, local subcooling $D T_{o}$ in $\mathrm{K}$ and inner diameter $D$ in $\mathrm{m}$. As can be seen, the velocity and local subcooling have strong effects on the $\mathrm{CHF}$, and the diameter has a negative effect with the exponent $n=-0.35$. At lower pressure with $D T_{o}<35 \mathrm{~K}$, the trend of $\mathrm{CHF}$ with $D T_{o}$ appears weaker than larger subcooling due to larger bubble size and great pressure drop, and thus the results are not included in the present correlation [27]. 


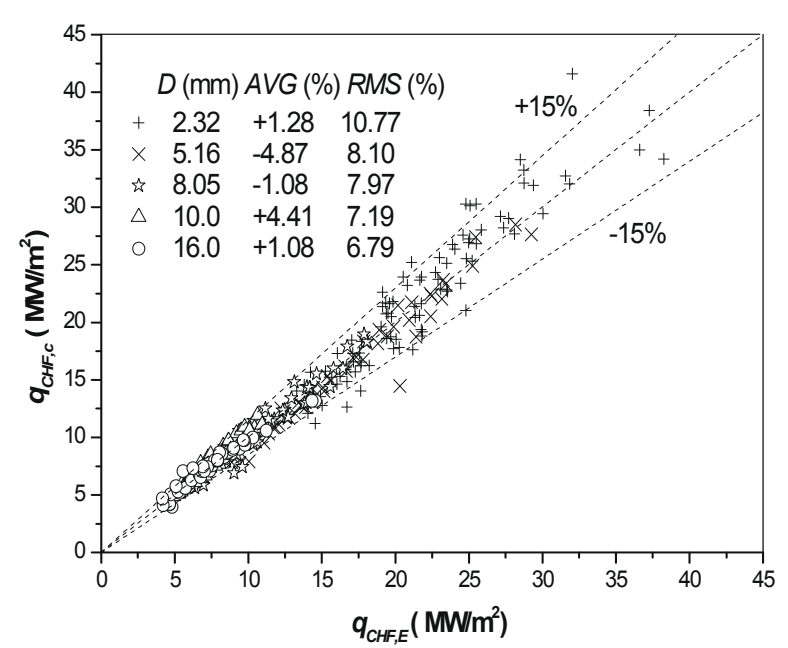

Fig. 8 Comparison of the experimental results with the calculations of Eq. (3) for lower pressures.

The comparison between the calculations of Eq. (3) and the experimental data is shown in Fig. 8. For $D=$ 2.32, 5.16, 8.05, 10.0 and $16.0 \mathrm{~mm}$, the $A V G$ is $+1.28 \%,-4.87 \%,-1.08 \%,+4.41 \%$ and $+1.08 \%$, and the $R M S$ is $10.77,8.10,7.97,7.19$ and $6.79 \%$, respectively. The total $A V G$ is $+0.29 \%$ and $R M S$ is $8.6 \%$.

\section{Mechanistic Model}

For subcooled flow boiling CHF, two types of physical models have been proposed: (i) the critical enthalpy models for bubbly layer [12-14], and (ii) the liquid sublayer dryout model for a thin liquid layer beneath an intermittent vapor blanket [15-17]. The first model is applied in subcooled or low saturated condition, and the latter in high subcooling condition. In the present investigation, the model is similar to the first one. At high subcooling, the thickness of bubbly layer is determinant, and it is evaluated by the diameter of single bubble detached from the surface, multiplying a constant. For extending this model to lower subcooling condition, the thickness of bubbly layer is modified to account for the bubble crowding. The reader refers to the previous paper for details [30]. The major equations of the present model are represented in this paragraph. The schematic diagram of transport between the bubbly layer and the subcooled liquid core is shown in Fig. 9.

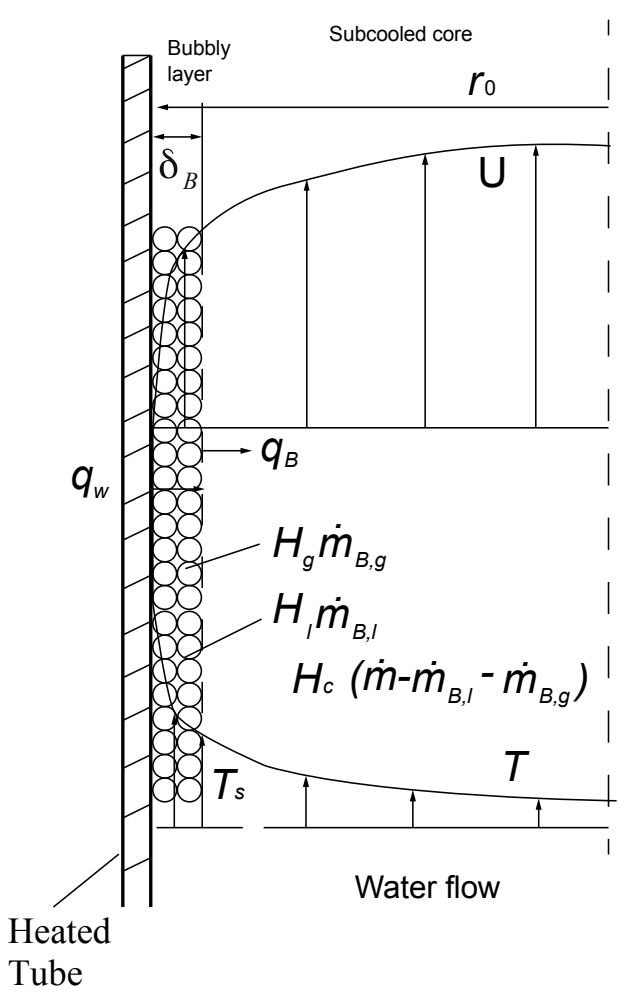

Fig. 9 Schematic diagram of transport between the bubbly layer and subcooled liquid core.

The thickness of bubbly layer is as:

$$
\delta_{B}=k_{1} D_{B}\left(1+k_{2} e^{-k_{3} P r Q}\right)
$$

where, the factor $k_{1}, k_{2}$ and $k_{3}$ are constants as, $k_{1}$ $=0.75, k_{2}=1,000$, and $k_{3}=1.0$. The $\operatorname{Pr}$ is the Prandtl number, $Q$ is a parameter group (see Eq. (14)). $D_{B}$ is the bubble or vapor blanket equivalent diameter, evaluated by [16]:

$$
D_{B}=\frac{32 \sigma f(\beta) \rho_{l}}{f G^{2}}
$$

where, the $\sigma$ is the surface tension in $\mathrm{N} / \mathrm{m}, \rho_{l}$ is the liquid density in $\mathrm{kg} / \mathrm{m}^{3}$ and $G$ is the mass flux in $\mathrm{kg} /\left(\mathrm{m}^{2} \cdot \mathrm{s}\right)$. The $f(\beta)$ is a function relative to the contact angle with surface. In the previous study, it is represented as:

$$
f(\beta)=0.03 \text { for } P \leq 10 \mathrm{MPa}
$$

and

$$
f(\beta)=0.03(1-0.055(P-10)) \text { for } P>10 \mathrm{MPa}
$$

where, $P$ is the pressure in MPa. 
In the present investigation, for $D=2.32 \mathrm{~mm}$, it is modified as:

$$
f(\beta)=0.03(1+1.5 / D) \text { for } D<3.0 \mathrm{~mm}
$$

The friction factor, $f$, is calculated by Colebrook-White equation combined with Levy's rough surface model [34], as:

$$
\frac{1}{\sqrt{f}}=1.14-2.0 \log \left(\frac{\varepsilon}{D}+\frac{9.35}{\operatorname{Re} \sqrt{f}}\right)
$$

where, $D$ is the tube diameter, $R e$ is the Reynolds number, and $\varepsilon$ is the surface roughness, accounted by $\varepsilon=0.75 D_{B}$.

The velocity distribution in the liquid core is represented by Karman's universal law, as in Celata's model [16]:

$$
\begin{gathered}
U^{+}=y^{+} \quad 0 \leq y^{+}<5 \\
U^{+}=5.0 \ln y^{+}-3.05 \quad 5 \leq y^{+}<30 \\
U^{+}=2.5 \ln y^{+}+5.5 \quad y^{+} \geq 30
\end{gathered}
$$

The temperature distribution in the liquid core is as follows [35]:

$$
\begin{gathered}
T_{0}-T=\operatorname{QPry}^{+} \quad 0 \leq y^{+}<5 \\
T_{0}-T=5 Q\left\{\operatorname{Pr}+\ln \left[1+\operatorname{Pr}\left(\frac{y^{+}}{5}-1\right)\right]\right\} \\
5 \leq y^{+}<30 \\
T_{0}-T=5 Q\left[\operatorname{Pr}+\ln (1+5 \operatorname{Pr})+0.5 \ln \left(\frac{y^{+}}{30}\right)\right] \\
y^{+} \geq 30
\end{gathered}
$$

with

$$
Q=\frac{q}{\rho_{l} C_{p l} U_{\tau}}
$$

The Eqs. (8)-(13) are assumed valid in the region of
$\delta_{B} \leq y \leq r$, and the $T_{0}$ is a referent value, determined by $T=T_{s}$ at $y=\delta_{B}$.

From the heat balance equation, the local enthalpy $H$ is calculated by:

$$
H=H_{i}+\frac{4 q L}{G D}
$$

and

$$
H \dot{m}=H_{C}\left(\dot{m}-\dot{m}_{B, g}-\dot{m}_{B, l}\right)+H_{g} \dot{m}_{B, g}+H_{l} \dot{m}_{B, l}
$$

where, $\dot{m}$ is the total flow rate, $\dot{m}_{B, g}$ and $\dot{m}_{B, l}$ are the vapor and liquid flow rate in the bubbly layer, respectively, $H_{g}$ and $H_{l}$ are the vapor and liquid enthalpy, and $H_{C}$ is the enthalpy of liquid core, calculated from the average temperature $T_{C}$, as:

$$
T_{C}=\frac{\int_{\delta_{B}}^{r} T U(r-y) \mathrm{d} y}{\int_{\delta_{B}}^{r} U(r-y) \mathrm{d} y}
$$

where, the $r$ is the radius of tube.

The $\dot{m}, \dot{m}_{B, g}$ and $\dot{m}_{B, l}$ are evaluated by:

$$
\begin{gathered}
\dot{m}=\pi D^{2} G / 4 \\
\dot{m}_{B, g}=\pi\left(D-\delta_{B}\right) \delta_{B} \alpha_{B} \rho_{g} \overline{U_{B}}
\end{gathered}
$$

and

$$
\dot{m}_{B, l}=\pi\left(D-\delta_{B}\right) \delta_{B}\left(1-\alpha_{B}\right) \rho_{l} \overline{U_{B}}
$$

where, $\alpha_{B}$ is the void fraction in the bubbly layer. It is taken as $\alpha_{B}=0.9$. The $\overline{U_{B}}$ is the average velocity of bubbly layer, estimated by:

$$
\overline{U_{B}}=0.5 U_{y=\delta}
$$

Calculation is started with a test heat flux $q$ $\left(<q_{s}\right)$, and the CHF is obtained through an iterative process. At low subcooling, the $q_{C}$ is close to the $q_{S}$, and not sensitive to $\delta_{B}$, thus the maximum value of $\delta_{B}$ is simply set as $0.1 D$. 
The calculations of this mechanistic model are also compared with the experimental results in Figs. 2, 3, 5-7. In Fig. 10, the calculations are compared with the experiment for higher pressures. The $A V G$ is $-1.2 \%$, $-0.12 \%$ and $+1.4 \%$, and the $R M S$ is $5.37 \%, 4.86 \%$ and $6.86 \%$ for the diameter of $4.62,7.98$ and $10.89 \mathrm{~mm}$, respectively. The total data are calculated with $A V G$ of $-0.16 \%$ and $R M S$ of $5.45 \%$.

For lower pressure with smaller diameter $D=2.32 \mathrm{~mm}$, the results are underestimated with the original model by about $11 \%$. Then, the function of contact angle is modified to the Eq. (6), and the results are improved properly. Fig. 11 shows the comparison of the

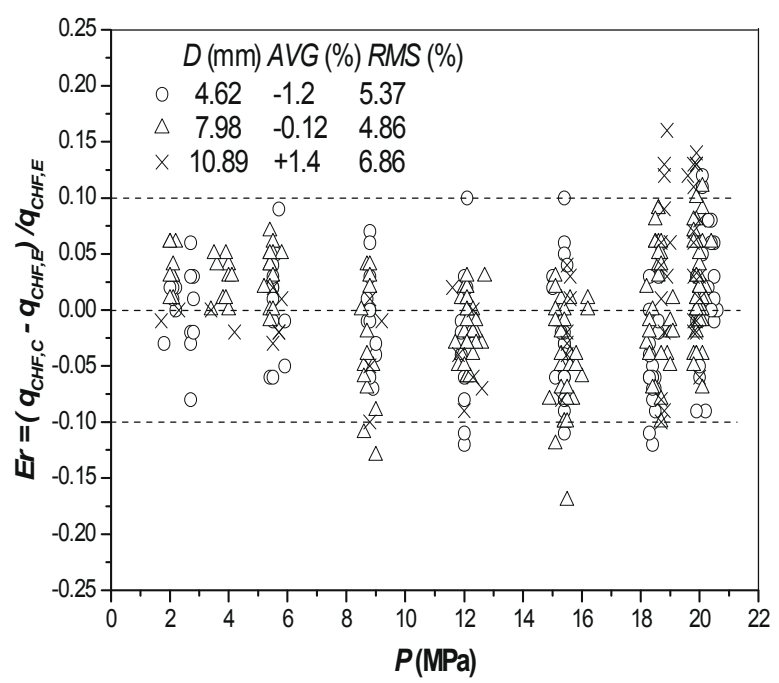

(a) calculations of this model with the experimental results for lower pressure. For all the 334 data points with $D T_{o}>35 \mathrm{~K}$, the $A V G$ is $+1.75 \%,-4.13 \%$, $+2.23 \%,+5.81 \%$ and $+5.12 \%$, and the $R M S$ is $7.33 \%$, $7.47 \%, 5.28 \%, 7.24 \%$ and $8.52 \%$ for $D=2.32,5.16$, $8.05,10.0$ and $16.0 \mathrm{~mm}$, respectively. The total data are calculated with $A V G$ of $+2.1 \%$ and $R M S$ of $7.2 \%$.

\section{Comparison with the Calculations of 95 CHF Look-up Table}

The 86 CHF-Look-up table was used in the reactor safety analysis code RELAP5/MOD3.3. The effect of diameter was accounted by a factor $(D / 8)^{n}$ with the $n$

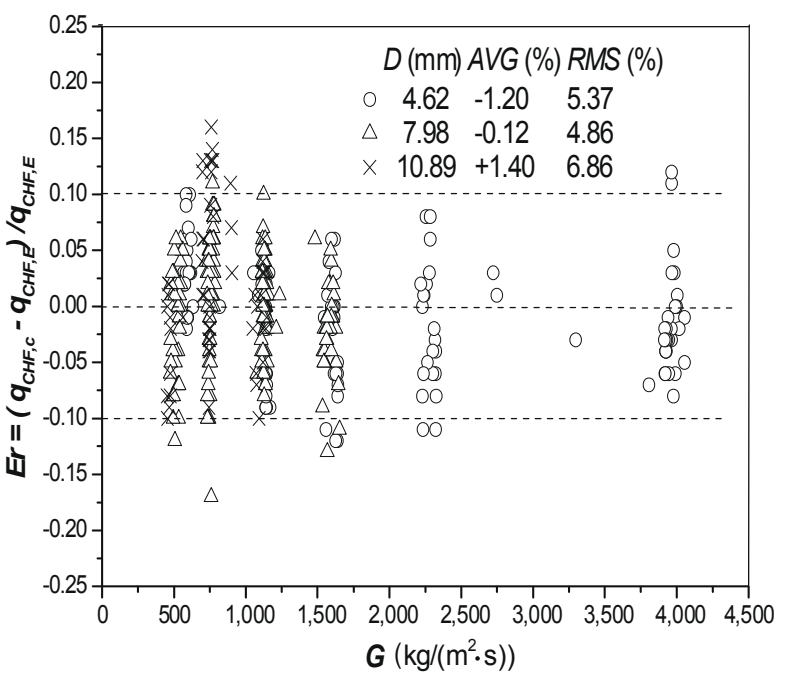

(b)

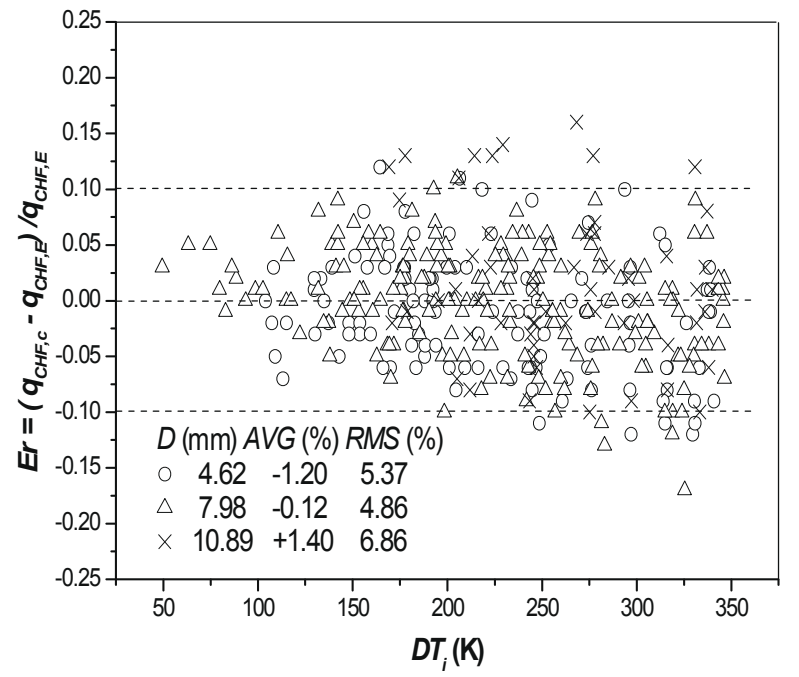

(c)

Fig. 10 Comparison of the calculations of mechanistic model with the experimental data for higher pressures. 


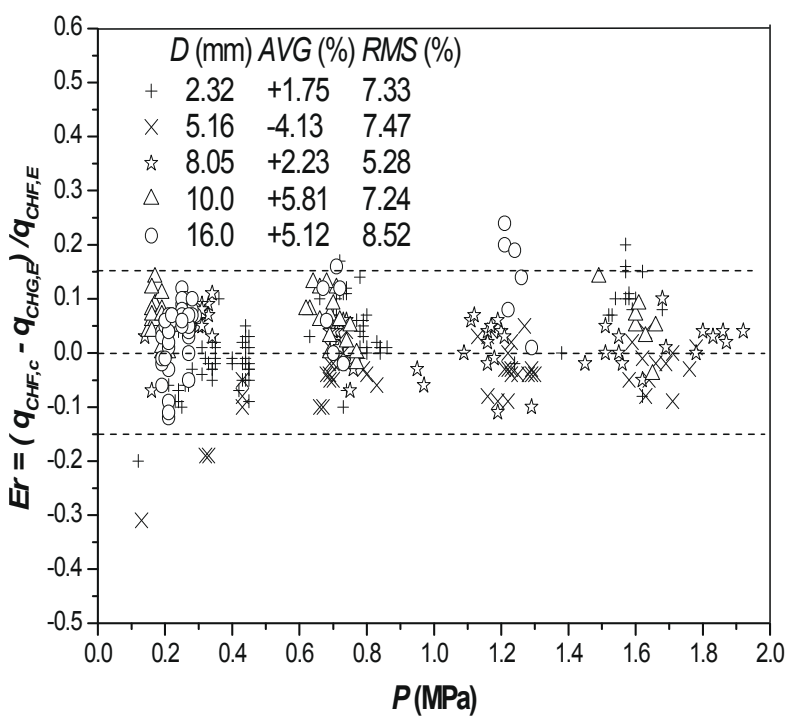

(a)

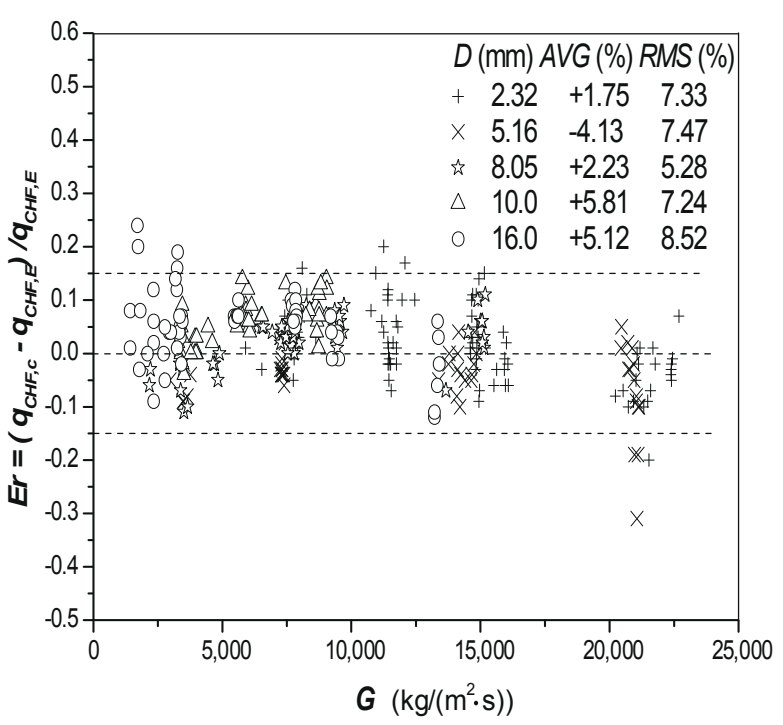

(b)

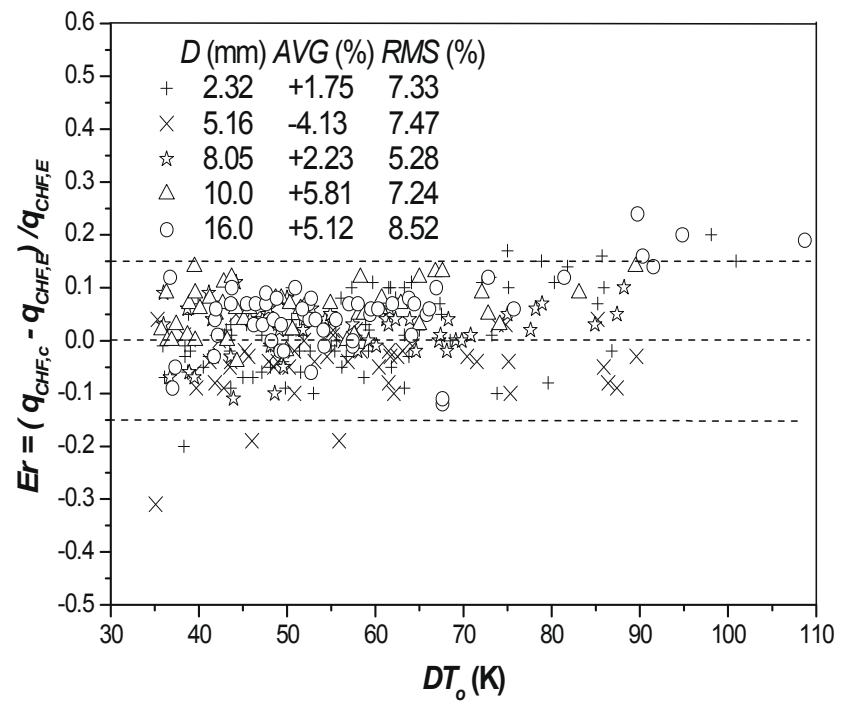

(c)

Fig. 11 Comparison of the calculations of the mechanistic model with the experimental results for $P<2 \mathrm{MPa}$.

ranged from -0.1 to -0.5 [36]. This look-up table was modified in 1995 [20]. The present experimental results are compared to the 95-CHF Look-up table in Fig. 12. At the normal operation condition of the PWRs (pressurized water cooled reactors) with $P=15.4 \mathrm{MPa}$ and $G=3,994 \mathrm{~kg} /\left(\mathrm{m}^{2} \cdot \mathrm{s}\right)$, the experimental results of $D=4.62 \mathrm{~mm}$ are close to the calculations by $95-\operatorname{LUT}(1)$ with $n=-0.35$, but are a little lower than 95-LUT(0) with $n=-0.5$. For the research reactors with $P=0.71 \mathrm{MPa}$ and $G=7,800 \mathrm{~kg} /\left(\mathrm{m}^{2} \cdot \mathrm{s}\right)$, the experimental results $q_{C H F, E}$, with $D=8.05 \mathrm{~mm}$ are also close to the $q_{C H F, c}$. At the conditions of $P=8.65 \mathrm{MPa}$ and $G=1,630 \mathrm{~kg} /\left(\mathrm{m}^{2} \cdot \mathrm{s}\right)$, which could occur at the accident condition of PWRs, the results of $D=7.98 \mathrm{~mm}$ are also close to the 95-LUT for $X_{o}<-0.04$, but some deviations of about $20 \%$ are observed at $X_{o}=-0.02$. At the conditions of $P=20 \mathrm{MPa}$, and $G=1,600 \mathrm{~kg} /\left(\mathrm{m}^{2} \cdot \mathrm{s}\right)$, which are similar to the normal operation conditions of the supercritical water-cooled reactors, the results $q_{C H F, E}$ of $D=7.98 \mathrm{~mm}$ are lower than the $q_{C H F, c}$ by about $30 \%-40 \%$. 


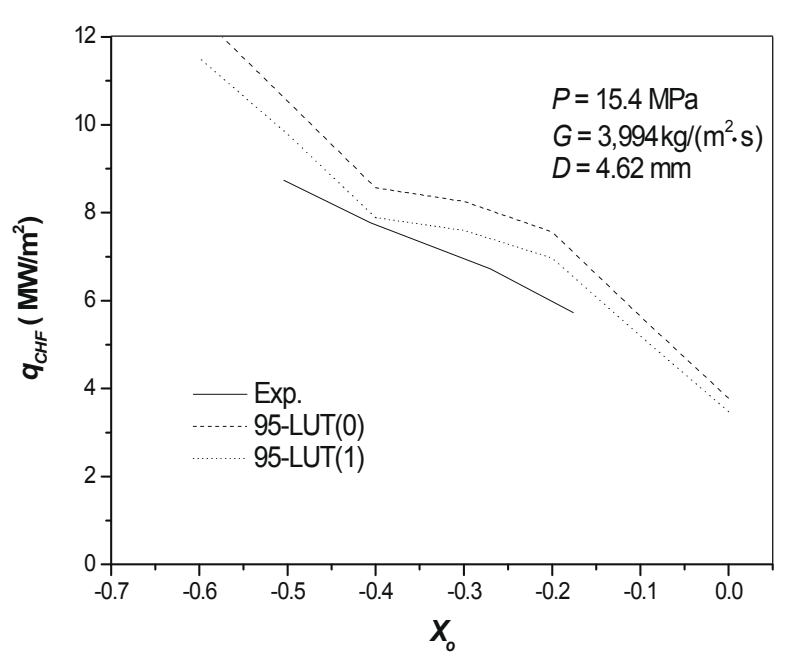

(a)

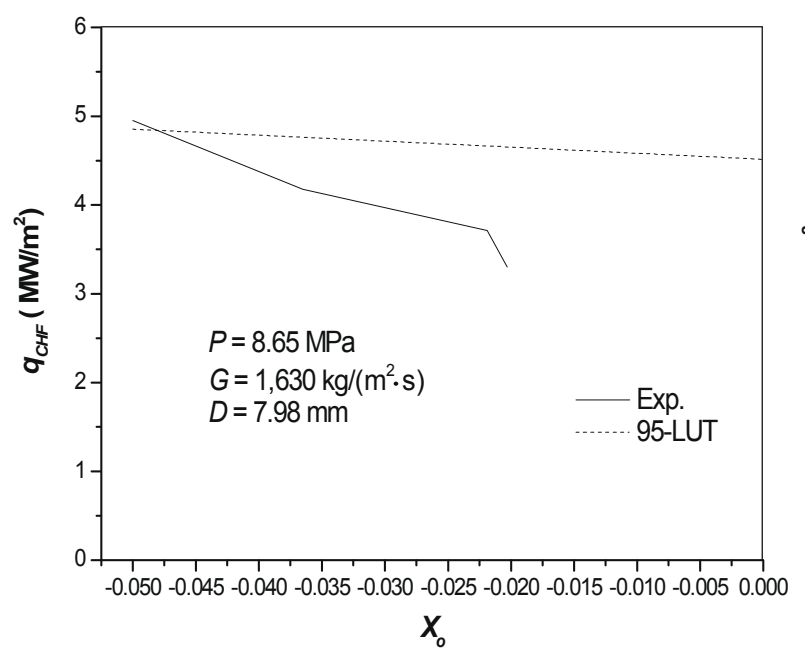

(c)

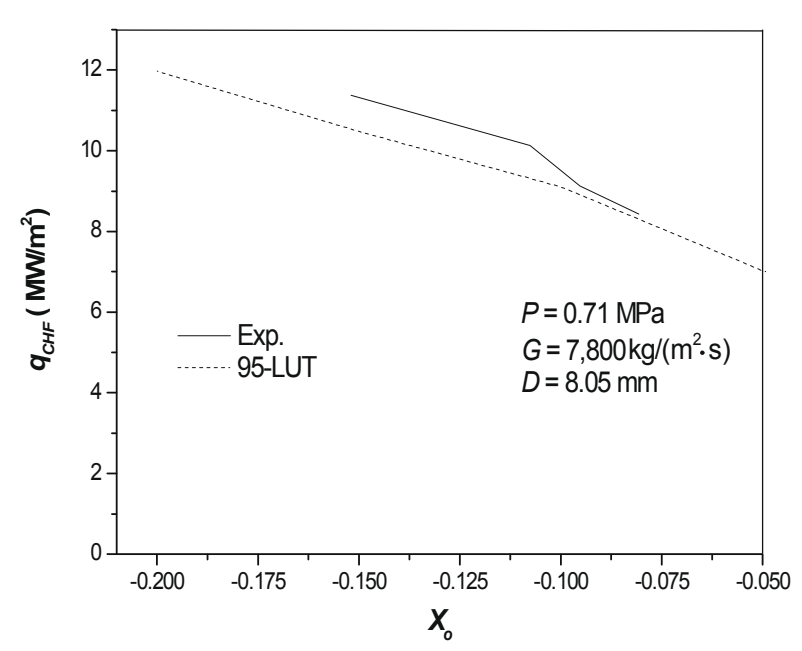

(b)

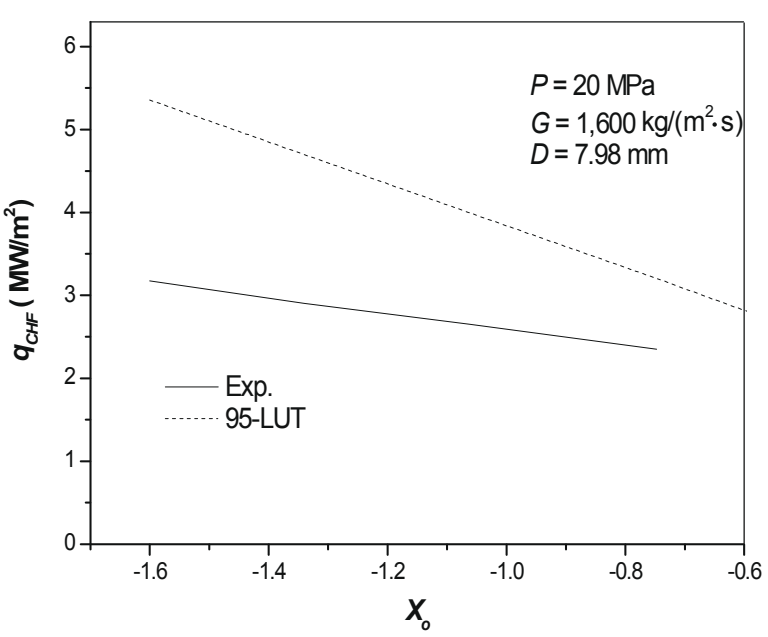

(d)

Fig. 12 Comparison of the present experimental results with the calculations of 95-Look-up table for different conditions (95-LUT(0) by $n=-0.5,95-L U T(1)$ by $n=-0.35)$.

\section{Conclusions}

The subcooled flow boiling CHF experiment is conducted in bare tubes of $D=2.32-16 \mathrm{~mm}$, covering the pressures ranging from atmosphere to near-critical point and wide ranges of flow conditions. The parametric trends are studied systematically. The experimental results are formulated by two empirical correlations and are validated by a mechanistic model. Major conclusions are achieved as follows:

- The CHF increases as mass flux and subcooling increasing. At higher pressure, the slope of $q_{C H F}$ with subcooling decreases. When the pressure tends toward the critical point the CHF decreases rapidly.

- For the same local conditions, higher $\mathrm{CHF}$ is attained in smaller diameter of tube, as accounted by $D^{-0.35}$ for the present conditions.

- For the present conditions, the critical heat flux is formulated by two empirical correlations for lower pressures and higher pressures, respectively.

- The mechanistic model, based on the limit of bubbly layer enthalpy, can predict the $\mathrm{CHF}$ for the whole range of conditions.

\section{References}

[1] Berglest, A. E. 1977. "Burnout in Boiling Heat Transfer. 

Atmosphere to Near-Critical Point

Part II: Subcooled and Low Quality Forced-Convection System." Nuclear Safety 18 (2): 154-67.

[2] Komori, Y., Kaminaga, M., Sakurai, F., Ando, H., Sudo, Y., Saito, M., and Futamura, Y. 1991. "Safety Criterion for Burnout of the Plate-Type Fuel in Pressurized Conditions." Presented at the Third Asian Symposium on Research Reactor, Kaken, Japan.

[3] IAEA-TECDOC, 1203. 2001. "Thermohydraulic Relationships for Advanced Water Cooled Reactors." IAEA-TECDOC, 1203.

[4] Gunther, F. C. 1951. "Photographic Study of Surface Boiling Heat Transfer to Water with Forced Convection." Trans. ASME 73 (2): 115.

[5] Mirshak, S., Durant, W. S., and Towell, R. H. 1959. "Heat Flux at Burnout." DP-355.

[6] Gambill, W. R. 1964. "HFIR Heat Transfer Studies of Turbulent Water in Thin Rectangular Channels." ORNL-3079.

[7] Petukhov, B. S. 1970. "Heat Transfer and Friction in Turbulent Pipe Flow with Variable Physical Properties." In Advances in Heat Transfer. New York: Academic Press, 503-65.

[8] Tolubinsky, V. L., Litoshenkp, A. K., and Shevtsov, V. L. 1970. "Heat Transfer Crisis at Water Boiling in Annular Channels with External and Internal Heating." Heat Transfer 1970 VI (B6): 11.

[9] Knoebel, D. H., Harris, S. D., Crain Jr, B., and Biderman, R. M. 1973. "Forced Convection Subcooled Critical Heat Flux.” DP-1306.

[10] Zeiganik, Y. A. 1994. "Critical Heat Flux and Pressure Drop under Forced Convection Boiling of Subcooled Water: Experimental Data." In Proceedings of the Tenth Int. Heat Transfer Conf., 581-6.

[11] Kirillov, P. L., and Yushenko, S. S. 1996. "Diameter Effect on CHF." Presented at the Second Research Coodination Meeting, IAEA Coordinated Research Program on Thermalhydraulics Relationships for Advanced Water Cooled Reactors, Vienna, Austria.

[12] Tong, L. S. 1968. "Boundary Layer Analysis of the Flow Boiling Crisis." Int. J. Heat Mass Transfer 11 (7): 1208-11.

[13] Weisman, J., and Pei, B. S. 1983. "Prediction of Critical Heat Flux in Flow Boiling at Low Qualities." Int. J. Heat Mass Transfer 26 (10): 1463-77.

[14] Tong, L. S., and Tang, Y. S. 1997. Boiling Heat Transfer and Two-Phase Flow. Washington: Taylor and Francis.

[15] Sudo, Y., and Kaminaga, M. 1993. "A New CHF Correlation Scheme Proposed for Vertical Rectangular Channels Heated from both Sides in Nuclear Research Reactors." Trans. ASMS 115 (2): 426-34.

[16] Celata, G. P., Cuma, M., Mariani, A., Simosini, M., and
Zummo, G. 1994. "Rationalization of Existing Mechanistic Models for the Prediction of Water Subcooled Flow Boiling Critical Heat Flux.” Int. J. Heat and Mass Transfer 37, Suppl. 1 (March): 347-60.

[17] Katto, Y. 1992. "A Prediction Model of Subcooled Water Flow Boiling CHF for Pressures in the Region 0.1-20.0 MPa." Int. J. Heat ans Mass Transfer 35 (5): 1115-23.

[18] Lee, C. H., and Mudawar, I. 1983. "A Mechanistic Critical Heat Flux Model for Subcooled Flow Boiling Based on Local Bulk Flow Conditions." Int. J. Multiphase Flow 14 (6): 711-28.

[19] Doroshchuk, V. E., Levitan, L. L., and Lantzman, F. P. 1975. "Investigation into Burnout in Uniformly Heated Tubes.” ASME Publication 75-WA/HT-22.

[20] Groeneveld, D. C., Leung, L. K. H., Kirillov, P. L., Bobkov, V. P., Smogalev, I. P., Vinogradov, V. N., Huang, X. C., and Royer, E. 1996. "The 1995 Look-up Table for Critical Heat Flux in Tubes." Nuclear Eng. Design 163 (1-2): 1-23.

[21] Vijayarangan, B. R., Jayanti, S., and Balakrishan, A. R. 2006. "Studies on Critical Heat Flux in Flow Boiling at Near Critical Pressures." Int. J. Heat and Mass Transfer 49 (1-2): 259-68.

[22] Hong, S. D., Chun, S. Y., Kim, S. Y., and Beak, W. P. 2004. "Heat Transfer Characteristics of an Internally Heated Annulus Cooled with R-134a Near the Critical Pressure." J. Korean Nuclear Society 36 (5): 403-14.

[23] Chun, S. Y., Hong, S. D., Kikura, H., and Aritomi, M. 2007. "Critical Heat Flux in a Heater Rod Bundle Cooled by R-134a Fluid Near the Critical Pressure." Nucl. Science and Technology 44 (9): 1189-98.

[24] Yin, S. T., Lui, T. J., Huang, Y. D., and Tain, R. M. 1988. "Measurements of Critical Heat Flux in Forced Flow at Pressures up to the Vicinity of the Critical Point of Water." In Proceedings of the 1988 National Heat Transfer Conference in USA, 501-6.

[25] Chen, Y., Zhou, R., and Chen, H. 1996. "Critical Heat Flux for Subcooled Flow in an Annulus with Bilateral Heating." In Heat Transfer Science and Technology 1996, edited by Wang Buxuan. New York: Hemisphere, 376-81.

[26] Chen, Y., Zou, L., and Yang, C. 2004. "Subcooled Boiling Critical Heat Flux in Annuli at Lower Pressure." Presented at the NUTHOS (Nuclear Thermal Hydraulics, Operations and Safety)-5, Nara, Japan.

[27] Chen, Y., Yang, C., and Mao, Y. 2005. “An Experimental Study of Subcooled Flow Boiling Critical Heat Flux of Water under Steady-State and Flow-Transient Conditions at Lower Pressure." In Proceedings of the 11th Int. Topical Meeting on Nuclear Reactor Thermal-Hydraulics (NURETH-11), 459.

[28] Chen, Y., Zhou, R., Hao, L., and Chen, H. 1997. "Critical 
Heat Flux with Subcooled Boiling of Water at Low Pressure." In Proceedings of the 8th Int. Topical Meeting on Nuclear Reactor Thermal-Hydraulics, 958-64.

[29] Chen, Y., Zhang, H., Guo, F., and Hao, L. 2000. "Subcooled Flow Boiling CHF in Tubes with Different Diameters." Presented at the Boiling 2000, Alaska, USA.

[30] Chen, Y. 2012. "Critical Heat Flux in Subcooled Flow Boiling of Water." In An Overview of Heat Transfer Phenomena, edited by Salim, N. K. Croatia: INTECH.

[31] Chen, Y., Yang, C., Zhao, M., Bi, K., Du, K., and Zhang, S. 2011. "Subcooled Boiling Critical Heat Flux of Water Flowing Upward in a Tube for Lower Flow and Pressure up to 20 MPa." In Proceedings of the 14th Int. Topical Meeting on Nuclear Reactor Thermal Hydraulics (NURETH-14), 620.

[32] Chen, Y., Yang, C., Zhao, M., Bi, K., Du, K., and Zhang,
S. 2011. "An Experimental Study of Critical Heat Flux in a Tube for Near-Critical Pressures." Presented at the 5th Int. Sym. SCWR (ISSCWR-5), Vancouver, Canada.

[33] Chen, Y., and Sheng, W. 1979. "The Application of Photocells in the Detection of CHF Occurrence." In The Calculations and Experiments in the Nuclear Reactor Thermal-Hydraulics. Beijing, China: Atomic Energy Press (in Chinese).

[34] Levy, S. 1967. "Forced Convection Subcooled Boiling-Prediction of Vapor Volumetric Fraction." Int. J. Heat Mass Transfer 10 (7): 951-65.

[35] Martinelli, R. C. 1947. "Heat Transfer to Molten Metals." Trans. ASME 69 (1947): 947-51.

[36] Nuclear Safety Analysis Division. 2001. "RELAP5/MOD3.3, Code Manual Vol. 1, Code Structure System Models and Solution Methods." NUREG/CR-5535/Rev 1-Vol I. 